\title{
FABRICATION AND CHARACTERIZATION OF ORAL THIN FILMS OF LEUKOTRINE RECEPTOR ANTAGONIST (LTRA)
}

\author{
*Kapoor $D^{1}$, Vyas RB ${ }^{1}$, Lad $C^{1}$, Patel $M^{1}$, Tyagi BL ${ }^{2}$ \\ ${ }^{1}$ Dr. Dayaram Patel Pharmacy College, Sardar baug, Station Road, Bardoli, Dist - Surat, Gujarat, India, Pin-394601 \\ ${ }^{2}$ Senior officer, Corporate Quality assurance, Sun Pharmaceuticals Limited, Haridwar, Uttarakhand, India
}

Received 10 Feb 2015; Review Completed 06 March 2015; Accepted 14 March 2015, Available online 15 March 2015

\begin{abstract}
:
Montelukast sodium is a leukotriene receptor antagonist (LTRA) used in maintenance treatment of asthma and to relieve symptoms of seasonal allergies. Fast dissolving drug delivery system offers a way out for those patients having difficulty in swallowing tablets/capsules etc. The present exploration was undertaken with the intention of formulating of the montelukast sodium fast dissolving oral thin films allowing fast reproducible drug dissolution in oral cavity thus bypassing first pass metabolism, to augment the expediency and acquiescence by the elderly and pediatric patients. Montelukast fast dissolving oral thin films were equipped by solvent casting method with using diverse film-forming agents like HPMC, PVP, PEG 400, glycerol as a plasticizer and mannitol as filler and sweetener. Oral thin films were characterized for weight variation, thickness, surface $\mathrm{pH}$, folding endurance, drug content, disintegration time, drug polymer compatibility (IR Study and in-vitro dissolution studies. Montelukast oral thin films based on evaluation studies HPMC showed optimum performance against other formulations. The prepared films were clear, transparent, and had a smooth surface. The surface $\mathrm{pH}$ was found to be in the range of 6.31 to 6.75 which is close to salivary $\mathrm{pH}$, which indicates that films may have less potential to irritate the oral mucosa, thereby they are comfortable. The drug content of all the films was in the range of 96.80 to 99.12 suggesting that drug was uniformly dispersed throughout all films. The In-vitro disintegration time of films prepared with HPMC was in the range of 25.38 to $39.12 \mathrm{sec}$. As the concentration of SSG increases the in-vitro disintegration time of the films decreases. It was accomplished that the fast dissolving oral thin films of montelukast can be prepared by solvent casting technique with improved dissolution rate, better patient compliance and effective therapy.
\end{abstract}

Keywords: Montelukast sodium, solvent casting, Folding endurance, in-vitro dissolution and oral thin films.

\section{INTRODUCTION:}

Oral delivery is currently the gold standard in the pharmaceutical industry where it is regarded as the safest, most convenient and an economical method of drug delivery having the highest patient compliance. ${ }^{1}$ The fast dissolving drug delivery systems came into existence in the early 1970's. Fast dissolving drug delivery systems have a major advantage over conventional dosage forms since the drug rapidly disintegrates and dissolves without the use of water1. Many patients have difficulty in swallowing tablets and capsules specially in cases of dysphagia, coughing, sudden allergic attacks or unavailability of water. Thus, to eliminate the drawbacks of tablets, fast dissolving films can be developed ${ }^{2,3}$. According to the film forming material characteristics, the manufacture of the dosage forms can present different critical issues. Common problems are caused by foaming during the film formation due to the heating of the material or solvent evaporation, the flaking during the slitting and the cracking in the cutting phase. Furthermore, the films should be stable to moisture overtime. Finally, to facilitate the handling they have to be flexible and exhibit a suitable tensile strength and do not stick to the packaging materials and fingers.
Formulation of these systems is usually straightforward; the polymer and drug are dissolved in a solvent and a film is cast by solvent evaporation. ${ }^{4,5}$

Despite of tremendous advancement in drug delivery the oral route of drug administration is the most important method of administration of drug for systemic effect. Oral route is most preferred route by medical practitioners and manufacturer due to highest acceptability of patients. About $60 \%$ of all dosage forms available are the oral solid dosage form. About $60 \%$ of all dosage forms available are the oral solid dosage form. The lower bioavailability, long onset time and dysphagia patients turned the manufacturer to the parenterals and liquid orals. But the liquid orals (syrup, suspension, emulsion etc) have the problem of accurate dosing mainly and parenterals are painful drug delivery, so most patient incompliance.

*Corresponding Author: Dr Devesh Kapoor Dr. Dayaram Patel Pharmacy College, Sardar baug, Station Road, Bardoli,

Dist - Surat, Gujarat, India, Pin-394601 E-mail id-dev7200@gmail.com Contact Info - +91-7874223242 
The montelukast sodium is a leukotriene receptor antagonist (LTRA) used for the maintenance treatment of asthma, chronic asthma attacks and to relive symptoms of seasonal allergies. The main drawback of conventional montelukast sodium formulation is that it undergoes hepatic first pass metabolism. Thus, it shows plasma or biological half-life 2.5 to $5.5 \mathrm{~h}$, thereby decreasing bioavailability upto $64 \%$. Montelukast Sodium is given in a dose of $10 \mathrm{mg}$ once daily. The present study is aim to formulate and characterized fast dissolving oral films of Montelukast Sodium for rapid dissolution of drug and absorption which may produce the rapid onset of action in the management of asthma and also to improve the bioavailability of the drug. It has extensive first-pass metabolism and show a very poor dissolution rates in order to overcome this problem preparation of oral thin films. The main objectives of the present study were to prepare and evaluate the oral thin films of montelukast sodium and to study the various formulation variables that affect in vitro performance.

\section{MATERIALS AND METHODS:}

\section{Materials:}

Montelukast sodium was obtained as a gift sample from Unimark remedies Ltd, Mumbai, India. HPMC E50 was procured from Yarrow chem. Products, Mumbai, India. PEG 400, PVP, PVA was obtained from S.D.Fine private limited, Mumbai, India. All the ingredients were of analytical grade.

\section{Method:}

\section{Fabrication of montelukast sodium oral thin films:}

The oral thin films of montelukast sodium were fabricated in laboratory using HPMC by solvent casting method. Hydroxy propyl methyl cellulose (HPMC) is known for its good film forming properties and has excellent acceptability. For the fabrication of films, propylene glycol was used as a plasticizer, glycerin as humectant and mannitol was used as a sweetener. The required quantity of montelukast sodium was dissolved in $10 \mathrm{ml}$ of distilled water containing various grades of HPMC to form polymeric dispersion. Briefly, propylene glycol, glycerin, aspartame and various polyhydric alcohols were dissolved in $5 \mathrm{ml}$ of $50 \% \mathrm{v} / \mathrm{v}$ ethanol. Alcoholic solution and the polymeric dispersion were mixed to obtain a homogeneous dispersion and $20 \mathrm{ml}$ of the dispersion was cast onto each polypropylene petri plate. The composition of various films is revealed in Table 1 . The dispersion was dried at $40-45{ }^{\circ} \mathrm{C}$. The films were carefully removed from petri plates and stored in an air tight glass bottle. The films were characterized for imperfections and cuts, peel ability without rupturing, folding and cracking endurance and surface roughness. ${ }^{10}$

Table 1 Different composition of oral thin films of montelukast sodium

\begin{tabular}{|l|l|l|l|l|l|l|l|l|}
\hline S.No & $\begin{array}{l}\text { Montelukast } \\
\text { sodium }(\mathbf{m g})\end{array}$ & $\begin{array}{l}\text { HPMC E } \\
\mathbf{5 0}(\mathbf{m g})\end{array}$ & $\begin{array}{l}\text { PVA(2\%) } \\
\mathbf{m l}\end{array}$ & $\begin{array}{l}\text { PVP } \\
(\mathbf{m g})\end{array}$ & $\begin{array}{l}\text { Glycerol } \\
(\mathbf{m l})\end{array}$ & $\begin{array}{l}\text { Ethanol } \\
(\mathbf{m l})\end{array}$ & $\begin{array}{l}\text { Water } \\
(\mathbf{m l}) \mathbf{u p t o}\end{array}$ & $\begin{array}{l}\text { PEG-400 } \\
(\mathbf{m l})\end{array}$ \\
\hline MOF1 & 20 & 100 & $5 \%$ & --- & 0.04 & 2 & 10 & 0.05 \\
\hline MOF2 & 20 & 100 & --- & --- & 0.04 & 2 & 10 & 0.05 \\
\hline MOF3 & 20 & 100 & $5 \%$ & 20 & 0.04 & 2 & 10 & 0.05 \\
\hline MOF4 & 20 & 100 & --- & --- & 0.04 & 2 & 10 & 0.05 \\
\hline MOF5 & 20 & 100 & $5 \%$ & 20 & 0.04 & 2 & 10 & 0.05 \\
\hline MOF6 & 20 & 100 & --- & --- & 0.04 & 2 & 10 & 0.05 \\
\hline
\end{tabular}

Characterization of oral films of montelukast sodium:

\section{Spectrum measurement:}

The standard stock solution of Montelukast sodium having concentration of $16 \mu \mathrm{g} / \mathrm{ml}$ in buffer

$0.5 \%$ SLS was scanned between $200-400 \mathrm{~nm}$ in UVVisible Spectrometer. The maximum

absorption $(\lambda \max )$ of Montelukast sodium peak was obtained at $345 \mathrm{~nm}$.

\section{FT-IR Studies}

Compatibility of drug and polymers was premeditated using Fourier Transform Infrared (FTIR) spectroscopy. FTIR Spectrum was recorded between $600-4000 \mathrm{~cm}-1$ using Shimadzu 160a, Kyoto, Japan by $\mathrm{KBr}$ Disc method.

\section{Surface pH:}

Film is slightly wet with the help of water. The $\mathrm{pH}$ is measured by bringing the electrode in contact with the surface of the oral film. This study is performed on three films of each formulation and means \pm S.D calculated. ${ }^{11}$

\section{Weight uniformity:}

The cast film was cut at different places and the weight of each film was checked with the help

of an electronic balance and the average weight was calculated. $^{12}$

Film thickness: The thickness of each film was measured using micrometer screw gauge at different positions of the film and the average was calculated. ${ }^{13}$

\section{Folding endurance:}

Folding endurance was determined by repeatedly folding the film at the same position until it

breaks. The number of times the films can be folded without breaking is termed as the folding

endurance value. ${ }^{14,15}$ 
Drug content of all batches of MTS thin films was determined by UV- spectrophotometric method. For this one strip of $5 \mathrm{~cm}^{2}$ was dissolved in $100 \mathrm{ml}$ of $\mathrm{pH} 6.8$ buffer. Then the solution was suitably diluted and the absorbance was recorded at $240 \mathrm{~nm}$.

\section{In vitro disintegration time:}

A glass Petri dish $(6.8 \mathrm{~cm}$ diameter $)$ was filled with 10 $\mathrm{ml}$ of water and the film was carefully placed in the center. The set up was left undisturbed. The time for the film to completely disintegrate into fine particles was noted. The test was performed four times on each formulation and mean value was reported. Wherever applicable, the mean disintegration times were subjected to statistical analysis by non-paired student $\mathrm{t}$ test. Differences in means were considered statistically significant at $\mathrm{P}<0.05{ }^{16}$

\section{In-vitro dissolution studies:}

In-vitro dissolution of fast dissolving film was studied in USP paddle dissolution test apparatus using phosphate buffer $\mathrm{pH} 6.8$ as the dissolution medium. The temperature was maintained at $37 \pm 0.5^{\circ} \mathrm{C}$ throughout the experiment. $5 \mathrm{ml}$ Sample was withdrawn at $50 \mathrm{sec}$ intervals and the same quantity was replaced with phosphate buffer of $\mathrm{pH}$ 6.8. The cumulative percentage of drug released was determined using UV visible spectrophotometer at $342 \mathrm{~nm} .{ }^{17}$

\section{Kinetic modeling of oral thin films:}

The dissolution profile of montelukast sodium oral thin films followed first order to ascertain the kinetic modeling of the drug release:

\section{Zero order}

In many of the modified release dosage forms, particularly sustained or controlled release dosage forms (those dosage forms that release the drug in planned, predictable and slower than the normal manner), is zero-order kinetic.

$$
\mathbf{m}=\mathbf{k} * \mathbf{t}
$$

Where, $\mathrm{k}$ is zero-order constant, $\mathrm{m}$ is the $\%$ drug unreleased and $\mathrm{t}$ is the time. The plot of $\%$ drug unreleased (released) versus time is the linear.

\section{First order}

Most conventional dosage forms exhibits this dissolution mechanism. Some modified release preparation, particularly prolonged release formulations, adheres to this type of dissolution pattern.

$$
\mathbf{m}=\mathbf{e a} * \mathbf{e}-\mathbf{b t}
$$

Where, $a$ is the intercept and $b$ is the slop. It assumes that the drug molecules, diffuses out through a gel like layer formed around the drug during the dissolution process. A plot of log \% drug release versus time is the linear.

\section{Stability studies:}

The purpose of the stability testing is to provide evidence on how the quality of a drug substance or drug product varies with time under the influence of a variety of environmental factors such as temperature, humidity and light, enabling recommended storage condition, retest periods and shelf life. The stability studies were carried out as per International Conference of harmonization $(\mathrm{ICH})$ Guidelines. Stability studies were carried out at $40^{\circ} \mathrm{C} / 75 \% \mathrm{RH}$ for 3 months. The optimized film formulations were packed in ambercolored bottles, which were tightly plugged with cotton and capped. They were then stored at $40^{\circ} \mathrm{C} / 75 \% \mathrm{RH}$ for 3months and evaluated for their physical appearance, drug content and in-vitro dispersion time at specified intervals of time. ${ }^{18}$

\section{RESULTS AND DISCUSSION:}

\section{Physical appearance and surface texture of film:}

All the films appeared uniform. All the films were found to be transparent and the surfaces of the films were smooth in nature. Thus it was concluded that the films were elegant and aesthetically appealing.

\section{FT-IR Studies:}

The possible interaction between drug and excipients used in the formulation development of montelukast sodium was studied by FTIR spectroscopy. The FTIR spectrum of montelukast depicts a characteristic absorption band at $3437 \mathrm{~cm}-1$ representing the presence of $\mathrm{OH}$ group. The $\mathrm{CH} 2$, C-N vibrations showed a characteristic absorption band in the region of $2926 \mathrm{~cm}$ 1 and $1265 \mathrm{~cm}-1$. The spectrum of montelukastpolymer physical mixtures showed absorption bands at $3414 \mathrm{~cm}-1,2926 \mathrm{~cm}-1$ and $1266 \mathrm{~cm}-1 \mathrm{OH}$, The CH2 and $\mathrm{C}-\mathrm{N}$. It indicates drug and drug containing physical mixture absorption bands were near that there was no chemical and physical change in the functional groups present in montelukast sodium. 


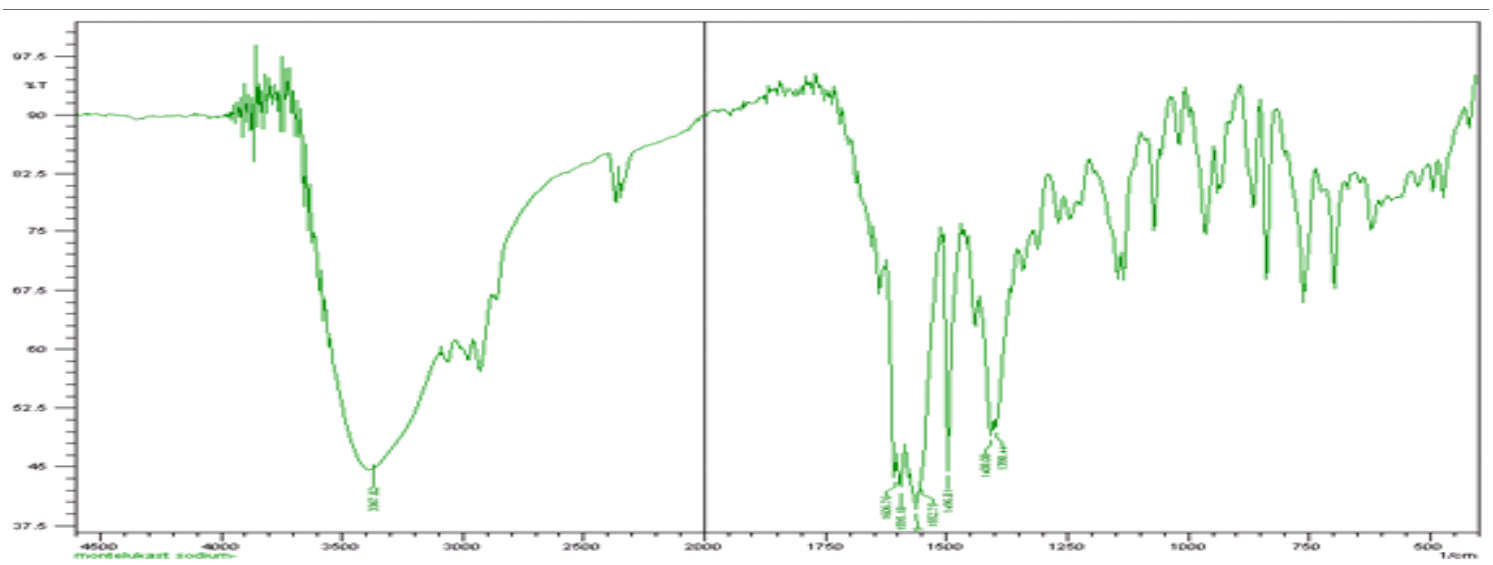

Figure 1: FT-IR spectra of montelukast sodium

\section{Surface pH:}

The surface $\mathrm{pH}$ was found to be in the range of 6.31 to 6.75 which is close to salivary $\mathrm{pH}$, which indicates that films may have less potential to irritate the oral mucosa, thereby they are comfortable. The results are given in Table 2 .

\section{Weight uniformity:}

Weight variation was carried out and this varied within the range of 39.08 to $43.24 \mathrm{mg}$. As per USP requirements, the formulations were found to meet the criteria for weight variation.

\section{Film thickness:}

All the films have uniform thickness throughout. The thickness of all the formulations ranged between 0.214 to $0.237 \mathrm{~mm}$. In all the cases the standard deviation values are very low which suggest the prepared films were uniform in thickness. The results are given in Table 2.

\section{Folding endurance:}

Folding endurance measures the ability of patch to withstand rupture, higher the folding endurance lower will be chances of film to rupture easily. Folding endurance value was more than 200 which indicated good elasticity of the films. The presence of plasticizer was the reason for this good elasticity. The results are given in Table 3.

\section{Drug content:}

Drug content was evaluated and it varied within the range of $96.80 \pm 2.87$ to $99.12 \pm 1.76$. The drug content was found to be low for MOF6 i.e. 96.80 and more for MF1 i.e. 99.12 As per USP requirements, drug content was found to be within the limits i.e. $85-115 \%$.

Table 2: Characterization parameters of oral film of montelukast sodium

\begin{tabular}{|l|l|l|l|l|l|l|}
\hline Formulation & \multicolumn{1}{|c|}{ MOF1 } & \multicolumn{1}{|c|}{ MOF2 } & \multicolumn{1}{c|}{ MOF3 } & \multicolumn{1}{c|}{ MOF4 } & \multicolumn{1}{c|}{ MOF5 } & MOF6 \\
\hline $\begin{array}{l}\text { Weight variation (mg) } \\
\pm \text { SD }\end{array}$ & $40.12 \pm 0.178$ & $43.24 \pm 0.065$ & $39.08 \pm 0.121$ & $40.78 \pm 0.351$ & $41.11 \pm 0.564$ & $42.66 \pm 0.306$ \\
\hline Thickness (mm) \pm SD & $0.214 \pm .0004$ & $0.237 \pm 0.005$ & $0.223 \pm 0.010$ & $0.219 \pm 0.026$ & $0.233 \pm 0.018$ & $0.220 \pm 0.008$ \\
\hline Surface pH \pm SD & $6.69 \pm 0.122$ & $6.45 \pm 0.272$ & $6.49 \pm 0.002$ & $6.31 \pm 0.008$ & $6.35 \pm 0.167$ & $6.75 \pm 0.135$ \\
\hline $\begin{array}{l}\text { Folding endurance } \\
\pm \text { SD }\end{array}$ & $266 \pm 4.12$ & $272 \pm 1.34$ & $262 \pm 3.23$ & $248 \pm 2.08$ & $265 \pm 1.11$ & $255 \pm 0.09$ \\
\hline $\begin{array}{l}\text { Disintegration time } \\
\pm \text { SD }\end{array}$ & $28.23 \pm 1.17$ & $25.58 \pm 2.00$ & $37.98 \pm 1.56$ & $34.65 \pm 2.31$ & $39.12 \pm 3.41$ & $38.98 \pm 4.11$ \\
\hline Drug content \pm SD & $99.12 \pm 1.76$ & $98.89 \pm 1.22$ & $97.54 \pm 0.09$ & $98.65 \pm 2.23$ & $99.44 \pm 1.31$ & $96.80 \pm 2.87$ \\
\hline
\end{tabular}

\section{In vitro disintegration time:}

In vivo Disintegrating time is defined as the time (seconds) at which a film breaks when brought into the contact with water or saliva. All the formulations were found to disintegrate within $60 \mathrm{sec}$. Formulation MOF2 showed less disintegration time i.e. $25.58 \mathrm{sec}$ and formulation MOF5 showed more disintegration time i.e. $39.12 \mathrm{sec}$.

\section{In-vitro dissolution studies:}

In vitro drug release was carried out in USP basket type dissolution apparatus. MOF5 formulation released more amount of drug i.e. 99.44 and formulation MOF6 released less amount of drug i.e. $96.80 \%$. Dissolution rate increases with decrease in disintegration time. In vitro dissolution studies graphs are mentioned in figure 2. More amount of drug release indicates rapid onset of action and hence faster relief. 


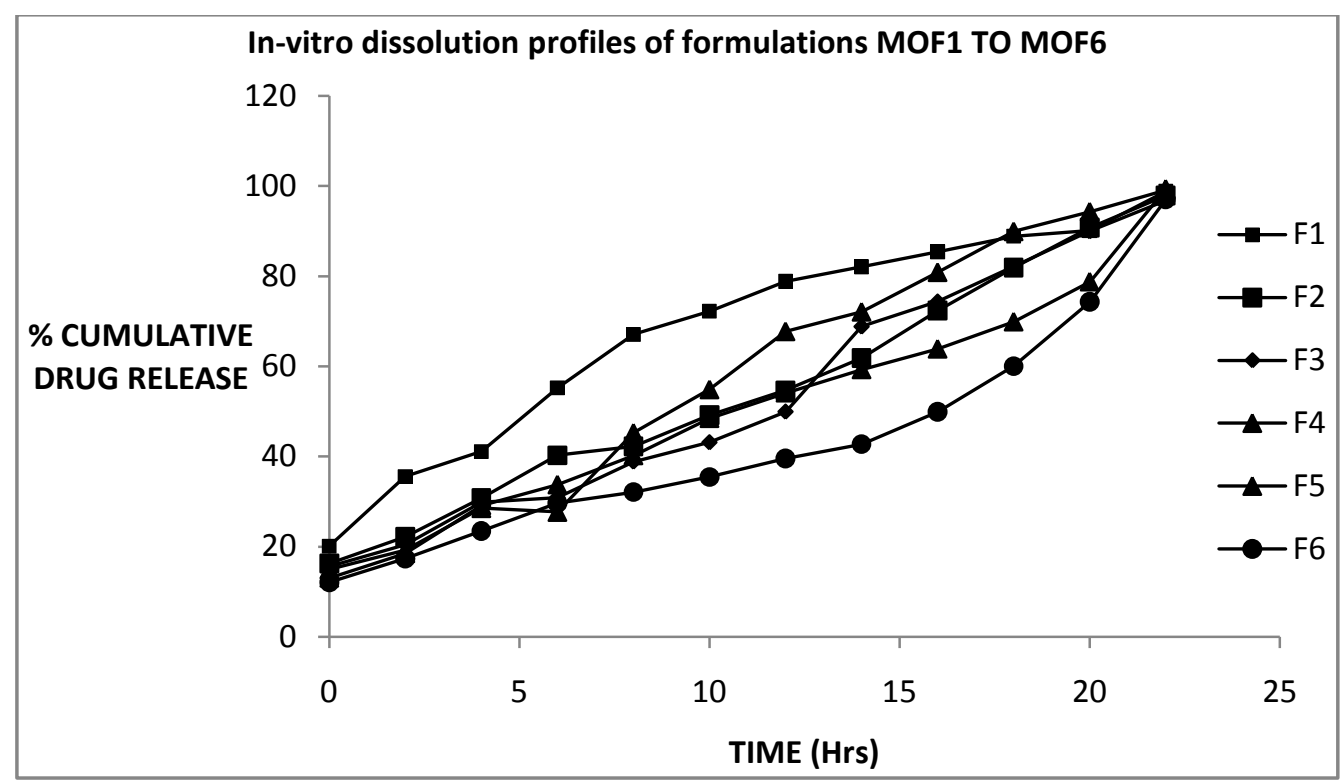

Figure 2: In-vitro dissolution profiles of formulation MOF1 to MOF6

\section{Kinetic modeling of oral thin films:}

Table 3 and fig 3 showing R2 values for zero order release and first order release. The values for first order were closer to 1 than those for zero order. So, it was assumed that all the formulations followed first order kinetics. The release is found concentration dependent.

Table 3: Kinetic modeling of montelukast sodium oral thin films

\begin{tabular}{|l|l|l|l|l|l|l|}
\hline Formulations & $\mathbf{K}^{-1}\left(\mathbf{M I N}^{-\mathbf{1}}\right)$ & $\mathbf{T}_{\mathbf{5 0}}$ & $\mathbf{R}$ & $\mathbf{D P}_{\mathbf{1 0}}$ & First order $\mathbf{R}^{\mathbf{2}}$ & ${\text { Zero order } \mathbf{R}^{\mathbf{2}}}$ \\
\hline MOF1 & 0.21 & 6.02 & 0.981 & 6592 & 0.910 & 0.812 \\
\hline MOF2 & 0.12 & 7.11 & 0.986 & 61.92 & 0.994 & 0.805 \\
\hline MOF3 & 0.03 & 13.8 & 0.988 & 70.11 & 0.947 & 0.614 \\
\hline MOF4 & 0.17 & 12.3 & 0.981 & 73.11 & 0.988 & 0.517 \\
\hline MOF5 & 0.04 & 10.1 & 0.971 & 78.97 & 0.991 & 0.588 \\
\hline MOF6 & 0.11 & 15.0 & 0.976 & 72.31 & 0.958 & 0.520 \\
\hline
\end{tabular}

\section{Stability studies:}

When the oral film preparation was stored either in the aluminum package or under unwrapped condition at $40 \circ \mathrm{C}$ and $75 \%$ in humidity for 4-8 weeks, no apparent changes in the shape, color or flexibility were observed.

Table 4: Stability studies data for oral films of montelukast sodium

\begin{tabular}{|l|l|l|l|l|l|l|}
\hline Formulations & \multicolumn{3}{|c|}{ MOF3 } & \multicolumn{3}{c|}{ MOF5 } \\
\hline & I Month & II Month & III Month & I Month & II Month & III Month \\
\hline $\begin{array}{l}\text { Disintegration } \\
\text { time }\end{array}$ & 20 & 24 & 22 & 25 & 27 & 24 \\
\hline Surface pH & 6.40 & 6.42 & 6.41 & 6.44 & 6.44 & 6.43 \\
\hline $\begin{array}{l}\text { Drug content } \\
(\%)\end{array}$ & 99.21 & 98.89 & 97.90 & 98.45 & 99.10 & 97.34 \\
\hline
\end{tabular}

\section{CONCLUSION:}

Fast dissolving films fulfill all the aforementioned requirements of potential solid oral dosage form for local delivery of montelukast sodium. In present research work, an attempt has been made to prepare (c) 2011-15, JDDT. All Rights Reserved mouth dissolving films of montelukast Sodium by solvent casting method using film forming polymer HPMC, PVA. Montelukast Sodium is freely soluble in water but its bioavailability is about $64 \%$. Based on the in-vitro disintegration time, formulation MOF1 and 
MOF2 were found to be promising and showed a disintegration time of 25.58 and $28.23 \mathrm{sec}$ respectively. However this FDF is useful for the improving of the

\section{REFERENCES:}

1. Rajkumar Goyal, Satyendra Singh Baghel, Ashish Pathak, Kshamashil Sharma, Gourav Tiwari and Rituraj Shivhare. A Review on Formulation \& Evaluation of Orodispersible Tablets (Fast Dissolving Tablet). WJPR. 2012; 1(3): 576-90.

2. Chowdary YA, Soumya M, Madhu BM, Aparna K, Himabindu P. A review of fast dissolving drug delivery systems- A pioneering drug delivery technology. Bull Env Pharmacol Life Scien, 2012; 1(12): 08-20.

3. Patil SL, Mahaparale PR, Shivnikar MA, Tiwari SS, Pawar KV, Sane PN. Fast dissolving oral films: An innovative drug delivery system. Int J Res \& Reviews Pharm \& Applied Sci 2(3): 482-496.

4. Ahmed MG, Narayana CR, Harish NM, Prabhakar P. Formulation and In-vitro evaluation of Chitosan films containing tetracycline for the treatment of periodontitis. Asian J Pharm 2009; 3;113- 9.

5. Hiroyoshi Shimoda, Kazumi Taniguchi, Misao Nishimura, Katsuhiko Matsuura , Tadao Tsukioka Hirotaka Yamashita, Naoki Inagaki, Kazuyuki Hirano, Mayumi Yamamoto Yasutomi Kinosada ,Yoshinori Itoh Preparation of a fast dissolving oral thin film containing dexamethasone:A possible application to antiemesis during cancer chemotherapy Eur J Pharm and Biopharmaceutics 2009 ; 73; 361-365.

6. Sean CS. Martindale-The Complete Drug Reference, 33rd edition; Pharmaceutical Press, London 2002, pp.455-456.

7. Anthony C, Moffat M, David Osselton, Brian Widdop. Clark's Analysis of Drugs and Poisons, 3rd Edition 2004, pp. 1299-1300.

8. Availablefromhttp://www.drugs.com/cons/Montelukast.html.

9. Raghavendra Rao NG, Mohd Abdul Hadi, Harsh A Panchal. A novel approach to sustained montelukast sodium release: bioavailability of the drug moreover, it revealed an excellent stability and dissolution profile.

Differentially coated mini-tablets in HPMC capsules. Int J Pharm Biomed Res 2011, 2(2), 90-97.

10. Satishbabu BK, Srinivasan BP. Preparation and evaluation of buccoadhesive films of atenolol. Indian J Pharm Sci 2008; 70; 175-9.

11. Dinge A. and Nagarsenker M. "Formulation and evaluation of fast dissolving films for delivery of triclosan to the oral cavity”, AAPS Pharm. Sci. Tech. 2008, 9(2), 349-356

12. Kapadia YD, Trambadiya DA, Patel AV, Patel VP. Formulation and evaluation of fast dissolving sublingual film of Metoprolol succinate. An Int J Pharma Sci 2013; 4(3): 140154.

13. Cilurzo FIE, Cupone P, Minghetti F, Selmin L. Montanari. 2008. Fast dissolving films made of maltodextrins. European J. Pharmaceutics and Biopharmaceutics. 70: 895-900.

14. Shinde AJ, Garala KC and More HN, Development and characterization of transdermal therapeutics system of tramadol hydrochloride, Asian J. Pharm. 2008; 4: 265 - 269.

15. Kapadia YD, Trambadiya DA, Patel AV, Patel VP. Formulation and evaluation of fast dissolving sublingual film of Metoprolol succinate. An Int J Pharma Sci 2013; 4(3): 140154.

16. Vijaya sri K, Rohini P, Reddy GK. Montelukast sodium oral thin films: Formulation and in vitro evaluation. Asian J Pharma \& Clinical Res 2012; 5(4): 266-270.

17. Koland M, Sandeep VP, Charyulu RN, Subrahmanyam EVS. The design and Characterisation of sublingual films of Ondansetron hydrochloride. Int J Chem Sci 2009; 7(4): 2927 2938.

18. Bhupinder B, Jangra S. Formulation and evaluation of fast dissolving sublingual films of Rizatriptan Benzoate. Int $\mathbf{J}$ Drug Dev \& Res 2012; 4(1): 133-143. 